\title{
Current Status of Childhood Hyperinsulinemic Hypoglycemia in Turkey
}

\author{
Zeynep Şıklar, Merih Berberoğlu \\ Ankara University Faculty of Medicine, Department of Pediatric Endocrinology, Ankara, Turkey
}

ABSTRACT

Congenital hyperinsulinism (CHI) is a rare disease characterized by dysregulated insulin secretion from pancreatic $\beta$-cells. Recurrent hypoglycemia can lead to neurological insult and permanent brain injury. Recently, there are important advances in understanding the genetic mechanisms, histological characteristics, imaging, and surgical techniques of congenital hyperinsulinemic hypoglycemia that could reflect to improvement in the clinical care of infants with this disorder. In Turkey, there is a high rate of consanguinity, thus, the incidence of $\mathrm{CHI}$ is expected to be high. Until now, there are no nationwide data regarding the disorder, and some individual case reports or case series had been published. Determining the characteristics of Turkish patients with $\mathrm{CHI}$ can help develop a different perspective on this rare disease. In this review, we evaluated the clinical and molecular characteristics of Turkish patients with $\mathrm{CHI}$ based on reports published in the literature. The most frequently seen mutations were ABCC8 gene mutations ( $n=37)$, followed by $H A D H(n=11)$ and KCNJ11 gene $(n=7)$ mutations. A total of 141 Turkish patients with $\mathrm{CHI}$ were reported until now. Among them, 115 patients had been genetically analyzed, and 56 of them had one of the mutation leading to hyperinsulinism.

Keywords: Hyperinsulinism, hypoglycemia in infancy, congenital hyperinsulinism, hyperinsulinemic hypoglycemia

Conflict of interest: None declared

Received: 11.02 .2016

Accepted: 09.05 .2016

\section{Introduction}

Hyperinsulinemic hypoglycemia $(\mathrm{HH})$ consist of a group of heterogeneous disorders characterized by unregulated insulin secretion from pancreatic $\beta$-cells (1). It is the commonest cause of both persistent and transient hypoglycemia in neonates and infants $(2,3,4)$. Because there can be severe brain damage related to hypoglycemia, it is vital to diagnose and treat patients with $\mathrm{HH}$ correctly $(1,2,3,4)$.

\footnotetext{
Address for Correspondence

Zeynep Şıklar MD, Ankara University Faculty of Medicine, Department of Pediatric Endocrinology, Ankara, Turkey

Phone: +903125956635 E-mail: zeynepsklr@gmail.com

OJournal of Clinical Research in Pediatric Endocrinology, Published by Galenos Publishing.
} 
The clinical presentation of $\mathrm{HH}$ can be very heterogeneous ranging from very subtle presentation to severe disease needing pancreatectomy $(2,3,4,5)$. It can be either permanent or transient; the permanent form is usually known as congenital. Transient forms of congenital hyperinsulinism ( $\mathrm{CHI}$ ) usually occur in newborns with certain risk factors like maternal diabetes mellitus, intrauterine growth retardation, perinatal asphyxia. Some case with transient $\mathrm{HH}$ might have HNF4A gene, HNF1A gene, or ATP-sensitive potassium $\left(\mathrm{K}_{\text {ATP }}\right)$ channel mutations.

$\mathrm{CHI}$ is the most severe and persistent form of hereditary $\mathrm{HH}(1,2,3,4)$. Persistent $\mathrm{CHI}$ can be caused by mutations in nine genes regulating the insulin secretion from the $\beta$-cells (ABCC8, KCNJ11, GLUD1, HADH, GCK, HNF4A, HNF1A, $S L C 16 A 1$, and UCP2 genes) $(6,7)$. The most common causes are mutations in the $A B C C 8$ and KCNJ11 which encode the SUR1 and Kir6. 2 subunits of the pancreatic $\beta$-cell $K_{\text {ATP }}$ channel $(2,3,4) . K_{\text {ATP }}$ channels in pancreatic $\beta$-cells regulate the flux of $K$ ions across cell membranes. Glucose phosphorylation by glucokinase controls glucose-regulated insulin secretion. Glucose 6 phosphatase produces ATP by getting metabolized. This leads to an increase in intracytosolic ATP:ADP ratio. Increased ATP:ADP ratio inhibits the activity of the $K_{\text {ATP }}$ channel. Following from this, ATP channel gets closed and membrane depolarization occurs. From this point on, voltage-dependent calcium channels open resulting in more calcium going into the beta cells. Higher concentrations of calcium trigger secretory granules to release insulin $(8,9)$.

Mutations in ABCC8 and KCNJ11 can be either autosomalrecessive or autosomal-dominant (10).

Histologically, $\mathrm{CHI}$ is classified in three subgroups: diffuse, focal, and atypical forms. Most of the times, diffuse form is inherited autosomal-recessively. Autosomal dominant hereditation is also seen but not as often. Focal form, which occurs sporadically, can be seen with the combination of paternal heterozygous germline mutation in one of the $A B C C 8$ and KCNJ11 genes and uniparental disomy of the maternal chromosome $11 \mathrm{p} 15$. In patients with atypical disease, the histological abnormalities may be diffuse with coexistence of normal and abnormal islets (9).

The incidence of $\mathrm{CHI}$ was reported as 1 in 40000 in the general population to 1 in 2500 in certain communities (11). In Turkey, there is a high rate of consanguinity, thus the incidence of $\mathrm{CHI}$ is expected to be high $(12,13)$. Until now, there are no nationwide data regarding this disorder, and only some individual case reports and studies including a total of 141 patients had been published $(6,13,14,15,16,17,18$, $19,20,21,22,23,24,25,26,27,28,29,30,31,32)$. Determining the characteristics of Turkish patients with $\mathrm{CHI}$ may gain a different perspective to this rare disorder.

In this review, we aimed to evaluate the all published papers reporting Turkish patients with $\mathrm{CHI}$ and to explore both diagnostic and follow-up characteristics of these patients.

\section{Methods}

The PubMed, SCOPUS, and Web of Science electronic databases were systematically searched from inception to February 10, 2016. The search terms were "hyperinsulinism" or "CHI" or "nesidioblastosis" or "hypoglycemia" or "persistent hyperinsulinemic hypoglycemia of infancy" or "hyperinsulinemic hypoglycemia of infancy" or "HI" or "hyperinsulinaemic" or "hyperinsulinemic" and "Turkey" or "Turkish". No search filters or language restrictions were imposed. All case reports, case series, and studies on Turkish patients with $\mathrm{HH}$ were evaluated. Papers reporting other than congenital or persistent $\mathrm{HH}$ were excluded from the analysis. The data of cases in authors' center were also given.

\section{General Characteristics of Patients}

A total of 18 manuscripts reporting Turkish patients with $\mathrm{CHI}$ had been published. A total number of 12 case reports including 1 to 3 patients were published between 1997 and 2016. Because some patients were presented in different papers, we counted them once. Only six papers reporting 4 to 35 patients' data had been published, including some patients individually reported before. The number of all reported Turkish patients was 141. Among them, 115 patients had undergone molecular genetic analysis, and 56 of them had one of the mutations leading to hyperinsulinism. A total of 26 patients had not undergone molecular studies $(6,13,14,15,16,17,18,19,20$, $21,22,23,24,25,26,27,28,29,30,31,32)$.

\section{Admission Characteristics of Turkish Patients}

It was reported that the most common presentation of $\mathrm{HH}$ is during the neonatal period $(1,2,3,4)$. These finding is similar to the characteristics of Turkish patients. The majority of reported Turkish patients were diagnosed during the neonatal period.

Delivery of macrosomic fetus is a sign of intrauterine hyperinsulinemic state. Among the reported Turkish cases, the rate of macrosomic babies was $34 \%$.

\section{Etiology of Turkish Hyperinsulinemic Hypoglycemia of Patients}

$\mathrm{HH}$ can be transient. Among the causes for transient form of $\mathrm{HH}$, maternal diabetes mellitus, intra-uterine growth retardation, perinatal asphyxia, erythroblastosis fetalis, maternal administration of drugs, intravenous glucose infusions during delivery, as well as Sotos syndrome can be counted $(10,33)$. There were only two papers reporting prolonged transient $\mathrm{HH}$ in Turkish children (15,32). Although transient $\mathrm{HH}$ usually resolves spontaneously in a few weeks, in some patients, the duration of hyperinsulinism can be protracted, requiring diazoxide treatment (10). In those patients, the mechanism for hyperinsulinism is not clear. Güven et al (32) reported a case series of $\mathrm{CHI}$ patients, and in 7 of 13 patients which responded to diazoxide therapy, treatment had been stopped between 15 
days to 12 years. Ağladıoğlu et al (15) presented $17 \mathrm{HH}$ cases in their series, eight of which had transient $\mathrm{HH}$; diazoxide therapy had been ceased between 3 to 154 months. No etiological or molecular genetic studies were done in these patients.

Recently, it has appeared that some transient $\mathrm{HH}$ patients have HNF4A gene, HNF1A gene, or $\mathrm{K}_{\text {ATP }}$ channel mutations $(16,34)$. HNF4-MODY and HNF1A-MODY were well-known subtypes of autosomal-dominant diabetes. Early postnatal $\mathrm{HH}$ could be accompanied in individuals with those mutations (34).

Huopio et al (35) described the first dominantly inherited ABCC8 mutation (E1507K, previously reported as E1506K) that caused $\mathrm{HH}$ in early life and predisposed to early-onset insulin deficiency. It was suggested that some adults with a dominant $\mathrm{K}_{\text {ATP }}$ channel mutation were asymptomatic, and these mutations could have been missed in infancy (36).

We followed up two siblings with transient $\mathrm{HH}$ who were heterozygous for $A B C C 8$ missense mutation, A1367D (c.4100C>A; p.Ala1367Asp). The clinical presentation of these patients with a dominant $A B C C 8$ mutation was milder than that of patients with the recessive form of the disease; they responded well to medical therapy. Both siblings have been diagnosed with autoantibody-negative diabetes mellitus during the prepubertal period following a remission of the $\mathrm{HH}$ in childhood. Their mother, maternal aunt, and maternal grandfather were also heterozygous for the same mutation. The mother was diagnosed with type 2 diabetes mellitus at the age of 28 years, and the maternal aunt and grandfather had a medical history of postprandial hypoglycemic attacks; there was no family history of hypoglycemia in neonatal period.

Another interesting patient that we diagnosed as transient $\mathrm{HH}$ was born after caesarian delivery with birth weight of $4250 \mathrm{~g}$. He had been diagnosed with nonketotic $\mathrm{HH}$ at 2 days of life (when blood sugar was $38 \mathrm{mg} / \mathrm{dL}$ and serum insulin level was found as $7.3 \mathrm{mlU} / \mathrm{mL}$ ). The patient responded well to diazoxide treatment in a dose of $10 \mathrm{mg} / \mathrm{kg} / \mathrm{day}$. During follow-up, diazoxide dose was tapered gradually and ceased at 3 months of life. Now, he is 2.5 years of age and good in condition. He was heterozygous for a novel KCNJ11 gene missense mutations and a KCNJ11 frameshift mutation [Exon1B/Exon1C;c.130G>A/c.405dup; p.Val144Met/p.Arg136fs (p.V44M/p.R136fs)]. The patient had inherited the p.V44M mutation from his clinically unaffected mother.

In the light of these findings, it should be kept in mind that transient $\mathrm{HH}$ in infancy can be related to $\mathrm{K}_{\text {ATP }}$ channel mutations, and diabetes mellitus may develop later in life.

\section{Genetic Mutations of Patients}

Molecular studies showed that the congenital form of $\mathrm{HH}$ is due to mutations in eight different genes (ABCC8, KCNJ11, GLUD1, CGK, HADH, SLC16A1, HNF4A, and UCP2). Most of the $\mathrm{CHI}$ cases are caused by $\mathrm{K}_{\text {ATP }}$ channel mutations. $\mathrm{K}_{\text {ATP }}$ channels in pancreatic $\beta$-cells are composed of four inwardrectifying potassium channel (Kir6.2) subunits and four high- affinity sulfonylurea receptor 1 (SUR 1) subunits (37). After excluding the recurrent reported cases, a total of 115 cases had been analyzed for genetic mutations; in 26 cases, no genetic analysis had been carried out. 44 of patients with mutation analysis done had $\mathrm{K}_{\text {ATP }}$ channel genes mutations (Figure 1). The most frequently seen mutations were $A B C C 8$ gene mutations $(\mathrm{n}=37)$, followed by $\mathrm{HADH}(\mathrm{n}=11), \mathrm{KCNJ} 11(\mathrm{n}=7)$ and GLUD1 $(n=1)$ gene mutations $(6,13,14,15,16,17,18,19,20,21,22,23,24$, $25,26,27,28,29,30,31,32)$.

ABCC8 gene mutations have been reported as the commonest cause of $\mathrm{CHI}$ by Demirbilek et al (24) in the largest cohort consisting of Turkish $\mathrm{CHI}$ patients. They estimated the frequency of $A B C C 8$ mutation in the $\mathrm{CHI}$ patients as $40 \%$ (14/35). In this cohort, eight different $A B C C 8$ mutations had been identified. One of the commonest mutations in their cohort (5/14) was p.L1171fs (c.3512del), a frameshift mutation on exon 28 of $A B C C 8$ gene. Güven et al (32) also reported that 9 of 12 mutation-positive patients had $A B C C 8$ gene mutation.

KCNJ11 gene mutations had been detected in seven patients (7/56). Three of them were reported in a cohort (24). The authors of this review detected three patients with KCNJ11 mutation. All except one patient with this mutation were diazoxide-unresponsive and required pancreatectomy. One diazoxide-unresponsive patient with KCNJ11 gene mutation responded well to octreotide therapy (32).

A female patient's follow-up in the authors' center revealed two novel mutations in the KCNJ11 gene in exon 1 which were

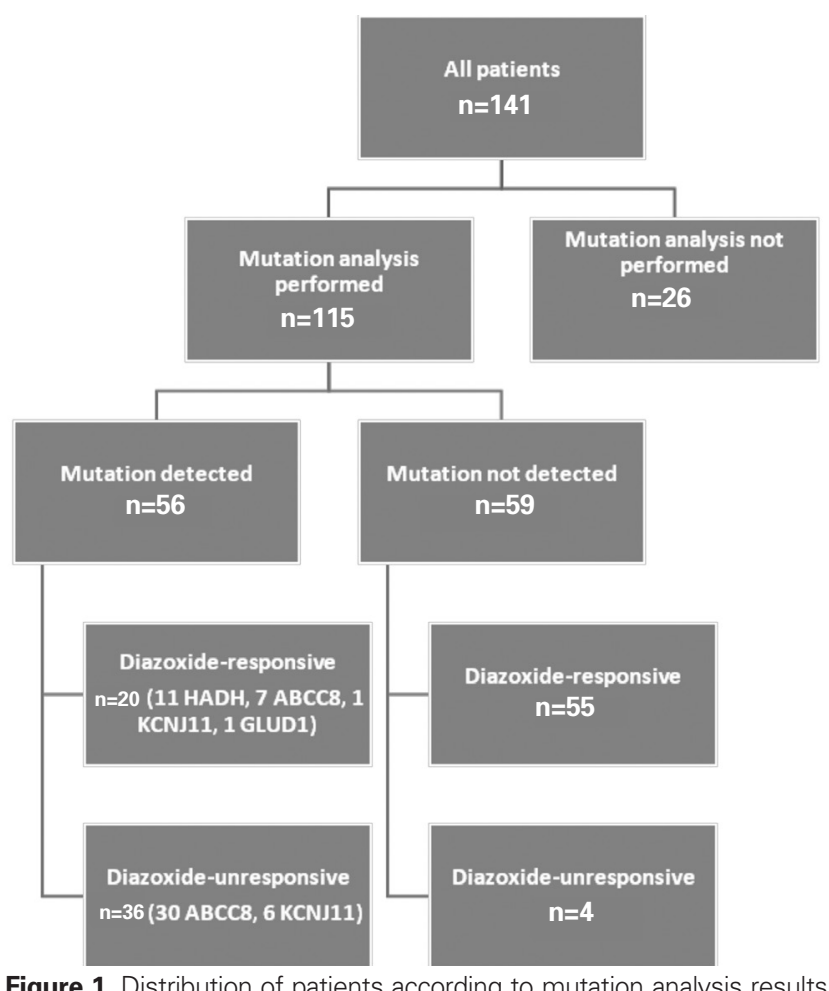

Figure 1. Distribution of patients according to mutation analysis results and diazoxide responsiveness 
Şıklar Z and Berberoğlu M.

Hyperinsulinemic Hypoglycemia in Turkey

paternally inherited (p.R221 H and p.Q299H). Her father was not clinically affected and mother had no $\mathrm{K}_{\text {ATP }}$ channel mutation. Interestingly, in this case, maternal loss of heterozygosity between chromosomes 11p15.5 and 11p15.1 covering the region (mosaic uniparental disomy) that may lead to BeckwithWiedemann syndrome was found. In histopathological evaluation, diffuse lesions were detected.

The distinction between focal and diffuse forms of hyperinsulinism cannot be made by clinical or biochemical means in cases with $\mathrm{CHI}$. Positron emission tomography/ computed tomography by 18 fluoro-L-DOPA (18F-DOPA PET/ CT) is a noninvasive scanning tool with the capability to distinct between focal and diffuse forms (38). Unfortunately, 18F-DOPA $\mathrm{PET} / \mathrm{CT}$ scanning is not available in Turkey.

We observed that $H A D H$ gene mutations were relatively frequent in Turkish $\mathrm{CHI}$ patients, accounting for $20 \%(11 / 56)$ of all mutation-studied cases $(6,13,24,32)$, despite the fact that the mutations in that gene are reported as a rare cause of recessively inherited $\mathrm{HH}(7,10)$. HADH gene encodes the mitochondrial enzyme L-3-hydroxyacyl-coenzyme A dehydrogenase $(H A D H)$. Loss-of-function mutations in the HADH gene cause short-chain L-3-hydroxyacyl-CoA (SCHAD) deficiency. The mechanism behind unregulated insulin secretion in SCHAD deficiency is not fully understood but may involve changes in protein-protein interactions with glutamate dehydrogenase (GDH) (6).

These patients exhibit severe protein (especially leucine) sensitivity, with some subjects having raised plasma levels of hydroxybutyrylcarnitine as well as elevated urinary levels of medium-chain dicarboxylic and 3-hydroxydicarboxylic metabolites and 3-hydroxyglutarate (6). The clinical presentation is mainly neonatal- or early infancy-onset $\mathrm{CHI}$, but mild lateonset phenotype can be seen $(6,10)$. So far, approximately 40 patients with $\mathrm{CHI}$ resulting from a mutation in the $H A D H$ gene have been reported, and all of them have responded well to diazoxide therapy (6).

Because the consanguinity is high in the Turkish population, occurrence of recessively inherited $H A D H$ gene mutation in increased rate seems to be inevitable. It is convenient that sequencing of $H A D H$ gene be recommended in all patients with diazoxide-responsive $\mathrm{HH}$.

The method for detection of HADH gene mutation is also important which could be different in the centers. Most of the Turkish patients $(n=8)$ with $H A D H$ gene mutation were reported by Flanagan et al (13). They detected deep intronic mutations of that gene by using next-generation sequencing analysis which have not been demonstrated before by Sanger sequencing.

Among the reported Turkish patients, there was no case with exercise-induced hyperinsulinism (SLC16A1), glucokinaseinduced hyperinsulinism, or mutations in the UCP2, HNF4A, and HNF1A genes, while one patient had GLUD1 gene mutation (32).

\section{Treatment Modalities of Turkish Patients}

For preventing hypoglycemia-related irreversible brain damage, aggressive and early intervention remains the mainstay of treatment in $\mathrm{HH}$. The first-line drug management of persistent
$\mathrm{CHI}$ is diazoxide therapy. Diazoxide binds to SUR1 component of $K_{\text {ATP }}$ channels resulting in their opening. It is effective in most of the $\mathrm{CHI}$ forms except in those due to recessive (and some dominant) inactivating mutations in $A B C C 8$ and $K C N J 11$ and in patients with focal $\mathrm{CHI}$ (10). The second-line medical treatment is octreotide therapy. If octreotide fails to control the hypoglycemia, surgical intervention is usually required.

Most of the Turkish patients with $\mathrm{CHI}$ were responsive to diazoxide treatment (100/141, $71 \%)$, while 18 of them had the transient form. Among patients with reported genetic mutation analysis $(n=115), 75$ were diazoxide-responsive.

All Turkish patients with HADH gene mutation were diazoxide-responsive, thus no surgical treatment was applied, as expected. Pancreatectomy was implemented in 28 of diazoxide-unresponsive $\mathrm{CHI}$ patients which accounts for $19.8 \%$ of all $\mathrm{CHI}$ patients. All of them, except one, had $\mathrm{K}_{\text {ATP }}$ channel mutations.

Pathological examination of pancreatic tissues revealed the diffuse form of hyperinsulinism in 27 of 28 cases. Moreover, the focal form of hyperinsulinism has been reported in the literature in almost half of all patients treated surgically (7); only one patient with focal form has been reported from our country (32).

Because 18F-DOPA PET/CT is not available in our country, genetic analysis would be important to discriminate the focal disease before the decision of pancreatectomy. Even in patients with mutation analysis indicating focal disease, this form might not be pathologically proven in every case. It is suspected that: Focal disease might not really have been absent among the patients. The pathological examination might have been insufficient in some patients.

It has been reported that pancreatectomy is associated with a high incidence of diabetes mellitus and pancreatic exocrine insufficiency. For that reason, surgical treatment should be reserved for the cases with unsuccessful medical treatment $(37,39)$. Among the reported Turkish patients with $\mathrm{CHI}$, there is very scarce long-term information after pancreatectomy with aspect to development of diabetes and other possible complications. In a case series, follow-up time was relatively low as near 6 years (32). In addition, there is no knowledge about disease-free survival. It would be important to demonstrate the follow-up of characteristics revealing the improvement in the management of these patients.

Very recently, a new medical treatment option has emerged for diffuse $\mathrm{CHI}$ unresponsive to diazoxide and/or octreotide treatment. The mammalian target of rapamycin inhibitor sirolimus has been successfully used in some diazoxide- and octreotide-unresponsive $\mathrm{CHI}$ patients. It reduces the pancreatic B-cell proliferation and inhibits insulin production (40).

Neurological outcome: One of the most important longterm complications of $\mathrm{CHI}$ is severe brain damage such as cerebral palsy, epilepsy, developmental delay $(1,2,3)$. Among the reported cases from Turkey, there are no extensive data about long-term neurological consequences. From the two largest series, it was seen that neurological sequelae were 
Sıklar Z and Berberoğlu M.

Hyperinsulinemic Hypoglycemia in Turkey

encountered in almost one third of patients (34\% and 29\%) $(15,24)$. Especially diazoxide-unresponsive patients were under high risk for development of neurological sequelae.

The most favorable neurological outcomes were seen in patients with $H A D H$ gene mutation. The longest follow-up was reported in a female patient with $H A D H$ gene mutation who had no neurological findings (6).

Early and aggressive treatment of patients with severe $\mathrm{CHI}$ is necessary to prevent brain damage, and diazoxide responsiveness gives an important clue for good prognosis and further treatment.

In conclusion, $\mathrm{CHI}$ is a heterogeneous disorder. $\mathrm{K}_{\text {ATP }}$ channel mutation is the most frequent etiological factor among mutationstudied Turkish patients with $\mathrm{CH}$. Patients with $\mathrm{HADH}$ gene mutation are relatively frequent among them. Transient form of $\mathrm{HH}$ in infancy could be caused by $\mathrm{K}_{\mathrm{ATP}}$ channel mutations, and diabetes mellitus may develop later in life. Because long-term neurological damage is high in diazoxide-unresponsive patients, early and prompt intervention is needed in such patients. There is no clear information and follow-up data, including development of diabetes, about patients who have undergone pancreatectomy. Multicenter studies are needed to obtain longterm follow-up characteristics of such patients at national base.

\section{Ethics}

Peer-review: Externally peer-reviewed.

\section{Authorship Contributions}

Concept: Zeynep Şıklar and Merih Berberoğlu, Design: Zeynep Şıklar and Merih Berberoğlu, Data Collection and Processing: Zeynep Şıklar, Analysis and Interpretation: Zeynep Şılar and Merih Berberoğlu, Literature Research: Zeynep Şıklar, Writing: Zeynep Şıklar and Merih Berberoğlu.

Financial Disclosure: The authors declared that this study received no financial support.

\section{References}

1. Darendeliler F, Bas F. Hyperinsulinism in infancy-genetic aspects. Pediatr Endocrinol Rev 2007;5:470.

2. Mohamed Z, Arya VB, Hussain K. Hyperinsulinaemic hypoglycaemia: genetic mechanisms, diagnosis and management. J Clin Res Pediatr Endocrinol 2012:4:169-181. Epub 2012 Oct 2

3. Dillon PA. Congenital hyperinsulinism. Curr Opin Pediatr 2013;25:357361.

4. Rahman SA, Nessa A, Hussain K. Molecular mechanisms of congenital hyperinsulinism. J Mol Endocrinol 2015;54:119-129. Epub 2015 Mar 2

5. Senniappan S, Arya VB, Hussain K. The molecular mechanisms, diagnosis and management of congenital hyperinsulinism. Indian $\mathrm{J}$ Endocrinol Metab 2013;17:19-30.

6. Çamtosun E, Flanagan SE, Ellard S, Şıklar Z, Hussain K, Kocaay P, Berberoğlu M. A Deep Intronic HADH Splicing Mutation (c.636+471G>T) in a Congenital Hyperinsulinemic Hypoglycemia Case: Long Term Clinical Course. J Clin Res Pediatr Endocrinol 2015;7:144-147.
7. Arya VB, Mohammed Z, Blankenstein O, De Lonlay P, Hussain K. Hyperinsulinaemic hypoglycaemia. Horm Metab Res 2014;46:157170. Epub 2014 Feb 20

8. James C, Kapoor RR, Ismail D, Hussain K. The genetic basis of congenital hyperinsulinism. J Med Genet 2009;46:289-299. Epub 2009 Mar 1

9. Sempoux C, Capito C, Bellanne-Chantelot C, Verkarre V, de Lonlay P, Aigrain Y, Fekete C, Guiot Y, Rahier J. Morphological mosaicism of the pancreatic islets: a novel anatomopathological form of persistent hyperinsulinemic hypoglycemia of infancy. J Clin Endocrinol Metab 2011;96:3785-3793. Epub 2011 Sep 28

10. Arya VB, Senniappan S, Demirbilek H, Alam S, Flanagan SE, Ellard S, Hussain K. Pancreatic endocrine and exocrine function in children following near-total pancreatectomy for diffuse congenital hyperinsulinism. PLoS One 2014;9:98054.

11. Glaser B, Thornton P, Otonkoski T, Junien C. Genetics of neonatal hyperinsulinism. Arch Dis Child Fetal Neonatal Ed 2000;82:79-86.

12. Tunçbilek E, Ozgüç M. Application of medical genetics in Turkey. Turk J Pediatr 2007;49:353-359.

13. Flanagan SE, Xie W, Caswell R, Damhuis A, Vianey-Saban C, Akcay T, Darendeliler F, Bas F, Guven A, Siklar Z, Ocal G, Berberoglu M, Murphy N, O'Sullivan M, Green A, Clayton PE, Banerjee I, Clayton PT, Hussain K, Weedon MN, Ellard S. Next-generation sequencing reveals deep intronic cryptic $A B C C 8$ and $H A D H$ splicing founder mutations causing hyperinsulinism by pseudoexon activation. Am J Hum Genet 2013:92:131-136. Epub 2012 Dec 27

14. Durmaz E, Flanagan SE, Parlak M, Ellard S, Akcurin S, Bircan I. A combination of nifedipine and octreotide treatment in an hyperinsulinemic hypoglycemic infant. J Clin Res Pediatr Endocrinol 2014;6:119-121.

15. Ağladıoğlu SY, Savaş Erdeve S, Çetinkaya S, Baş VN, Peltek Kendirci HN, Önder A, Aycan Z. Hyperinsulinemic hypoglycemia: experience in a series of 17 cases. J Clin Res Pediatr Endocrinol 2013;5:150-155.

16. Oçal G, Flanagan SE, Hacihamdioğlu B, Berberoğlu M, Siklar Z, Ellard S, Savas Erdeve S, Okulu E, Akin IM, Atasay B, Arsan S, Yağmurlu A. Clinical characteristics of recessive and dominant congenital hyperinsulinism due to mutation(s) in the $A B C C 8 / K C N J 11$ genes encoding the ATP-sensitive potasium channel in the pancreatic beta cell. J Pediatr Endocrinol Metab 2011;24:1019-1023.

17. Demirel F, Unal S, Çetin II, Esen I, Arasli A. Pulmonary hypertension and reopening of the ductus arteriosus in an infant treated with diazoxide. J Pediatr Endocrinol Metab 2011;24:603-605.

18. Bulbul A, Bolat F, Comert S, Demirin H, Tanik C, Bulbul L, Nuhoglu A, Dokucu Al. Persistent hyperinsulinemic hypoglycemia with left ventricular hypertrophy and dysrhythmia: a case report. Fetal Pediatr Pathol 2010;29:165-171.

19. Camurdan MO, Cinaz P, Serdaroğlu A, Bideci A, Demirel F. Persistent hyperinsulinemic hypoglycemia presenting with a rare complication: West syndrome. J Pediatr Endocrinol Metab 2004;17:1465-1468.

20. Darendeliler F, Bundak R, Bas F, Saka N, Günöz H. Long-term diazoxide treatment in persistent hyperinsulinemic hypoglycemia of infancy: a patient report. J Pediatr Endocrinol Metab 1997;10:79-81.

21. Apak RA, Yurdakök M, Oran O, Senocak ME, Cağlar M. Preoperative use of octreotide in a newborn with persistent hyperinsulinemic hypoglycemia of infancy. J Pediatr Endocrinol Metab 1998;11(Suppl 1):143-145.

22. Baş F, Darendeliler F, Demirkol D, Bundak R, Saka N, Günöz H. Successful therapy with calcium channel blocker (nifedipine) in persistent neonatal hyperinsulinemic hypoglycemia of infancy. J Pediatr Endocrinol Metab 1999;12:873-878. 
Şıklar Z and Berberoğlu M.

Hyperinsulinemic Hypoglycemia in Turkey

23. Darendeliler F, Fournet JC, Baş F, Junien C, Gross MS, Bundak R, Saka N, Günöz H. ABCC8 (SUR1) and KCNJ11 (KIR6.2) mutations in persistent hyperinsulinemic hypoglycemia of infancy and evaluation of different therapeutic measures. J Pediatr Endocrinol Metab 2002;15:993-1000.

24. Demirbilek H, Arya VB, Ozbek MN, Akinci A, Dogan M, Demirel F, Houghton J, Kaba S, Guzel F, Baran RT, Unal S, Tekkes S, Flanagan SE, Ellard S, Hussain K. Clinical characteristics and phenotypegenotype analysis in Turkish patients with congenital hyperinsulinism; predominance of recessive $\mathrm{K}_{\text {ATP }}$ channel mutations. Eur J Endocrinol 2014;170:885-892. Epub 2014 Mar 31

25. Celik N, Cinaz P, Emeksiz HC, Hussain K, Çamurdan O, Bideci A, Döğer E, Yüce Ö, Türkyılmaz Z, Oğuz AD. Octreotide-induced long QT syndrome in a child with congenital hyperinsulinemia and a novel missense mutation (p.Met115Val) in the ABCC8 gene. Horm Res Paediatr 2013;80:299-303. Epub 2013 Sep 27

26. Yildizdas D, Erdem S, Küçükosmanoglu O, Yilmaz M, Yüksel B. Pulmonary hypertension, heart failure and neutropenia due to diazoxide therapy. Adv Ther 2008;25:515-519.

27. Bulun A, Sarici SU, Soyer OU, Tekşam O, Yurdakök M, Cağlar $\mathrm{M}$. The triad of nesidioblastosis, congenital neuroblastoma and glomerulocystic disease of the newborn: a case report. Turk J Pediatr 2005;47:298-302.

28. Baş VN, Ozkan M, Zenciroğlu A, Cavuşoğlu YH, Cetinkaya S, Aycan Z. Seizure due to somatostatin analog discontinuation in a case diagnosed as congenital hyperinsulinism novel mutation. J Pediatr Endocrinol Metab 2012;25:553-555.

29. Ince DA, Sahin NM, Ecevit A, Kurt A, Kinik ST, Flanagan SE, Hussain $\mathrm{K}$, Tarcan A. Congenital hyperinsulinism in a newborn with a novel homozygous mutation (p.Q392H) in the ABCC8 gene. J Pediatr Endocrinol Metab 2014;27:1253-1255.

30. Üstün NU, Dilli $D$, Kundak $A A$, Okumus N, Erdoğan $D$, Apaydın $S$. A novel mutation in $A B C C 8$ gene in a newborn with congenital hyperinsulinism -a case report. Fetal Pediatr Pathol 2013;32:412-417. Epub 2013 Apr 22
31. Şimşek E, Binay Ç, Flanagan SE, Ellard S, Hussain K, Kabukçuoğlu S. Congenital hyperinsulinism presenting with different clinical, biochemical and molecular genetic spectra. Turk J Pediatr 2013;55:584590.

32. Güven A, Cebeci AN, Ellard S, Flanagan SE. Clinical and Genetic Characteristics, Management and Long-Term Follow-Up of Turkish Patients with Congenital Hyperinsulinism. J Clin Res Pediatr Endocrinol 2016;8:197-204. Epub 2015 Dec 18

33. Nakamura $Y$, Takagi $M$, Yoshihashi $H$, Miura M, Narumi $S$, Hasegawa T, Miyake $Y$, Hasegawa $Y$. A case with neonatal hyperinsulinemic hypoglycemia: It is a characteristic complication of Sotos syndrome. Am J Med Genet A 2015;167:1171-1174. Epub 2015 Feb 25

34. Pearson ER, Boj SF, Steele AM, Barrett T, Stals K, Shield JP, Ellard S, Ferrer J, Hattersley AT. Macrosomia and hyperinsulinaemic hypoglycaemia in patients with heterozygous mutations in the HNF4A gene. PLoS Med 2007;4:118

35. Huopio H, Reimann F, Ashfield R, Komulainen J, Lenko HL, Rahier J, Vauhkonen I, Kere J, Laakso M, Ashcroft F, Otonkoski T. Dominantly inherited hyperinsulinism caused by a mutation in the sulfonylurea receptor type 1. J Clin Invest 2000;106:897-906.

36. Pinney SE, MacMullen C, Becker S, Lin YW, Hanna C, Thornton P, Ganguly A, Shyng SL, Stanley CA. Clinical characteristics and biochemical mechanisms of congenital hyperinsulinism associated with dominant $\mathrm{K}_{\text {ATP }}$ channel mutations. J Clin Invest 2008;118:28772886.

37. Rozenkova K, Guemes M, Shah P, Hussain K. The Diagnosis and Management of Hyperinsulinaemic Hypoglycaemia. J Clin Res Pediatr Endocrinol 2015;7:86-97.

38. Laje P, States LJ, Zhuang H, Becker SA, Palladino AA, Stanley CA, Adzick NS. Accuracy of PET/CT Scan in the diagnosis of the focal form of congenital hyperinsulinism. J Pediatr Surg 2013;48:388-393.

39. Pierro A, Nah SA. Surgical management of congenital hyperinsulinism of infancy. Semin Pediatr Surg 2011;20:50-53.

40. Senniappan S, Alexandrescu S, Tatevian N, Shah P, Arya V, Flanagan S, Ellard S, Rampling D, Ashworth M, Brown RE, Hussain K. Sirolimus therapy in infants with severe hyperinsulinemic hypoglycemia. N Engl J Med 2014;370:1131-1137. 